\title{
O USO DA TABELA PERIÓDICA COMO RECURSO LÚDICO FACILITADOR DA APRENDIZAGEM DE UMA DISCENTE COM SÍNDROME DE DOWN
}

\author{
EL USO DE LA TABLA PERIÓDICA COMO UN RECURSO DE JUEGO \\ FAVORABLE PARA APRENDER A UN ESTUDIANTE DE SÍNDROME ABAJO
THE USE OF THE PERIODIC TABLE AS A FAVORABLE PLAYING RESOURCE FOR LEARNING A DOWN SYNDROME STUDENT

\begin{abstract}
Bruno Galdino Lopes; José Leonardo Alves Ferreira; Márcio Jean Fernandes Tavares; Niely Silva de Souza; Alessandra Marcone Tavares Alves de Figueirêdo
\end{abstract}

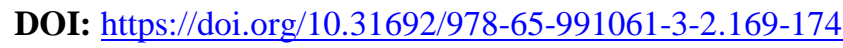

\section{INTRODUÇÃO}

O número de matrículas em escolas regulares no Brasil, de pessoas que apresentam Síndrome de Down (SD), aumentou consideravelmente nos últimos 10 anos (OLIVEIRA, 2015). Entretanto, cada vez mais nota-se a necessidade de ampliar as discussões e apoio por uma política pública de inclusão efetiva de discentes que apresentam esta deficiência, assim como outras. Sob esse viés, diante das necessidades observadas no processo de ensino e aprendizagem e dos debates realizados, a educação brasileira deve ser reestruturada para que os discentes com SD possuam direito à uma educação de qualidade, a qual lhes permitam experimentar, de forma exitosa, o ambiente escolar. Dessa maneira, a inclusão tornou-se uma discussão necessária nos cursos de formação de professores pois, é neste momento, que o futuro docente precisa refletir sobre as realidades encontradas nas escolas e pensar em estratégias que possam auxiliar a pessoa com deficiência na sua escolarização. Uma das estratégias encontradas é utilizar recursos como a contextualização, as Tecnologias da Informação e Comunicação TIC's, aulas experimentais, bem como fazer uso da ludicidade, trabalhando com o concreto.

Neste contexto, o objetivo desse trabalho foi aplicar uma Tabela Periódica, no intuito de auxiliar uma educanda com SD, na aprendizagem de conceitos químicos referentes ao conteúdo "Tabela Periódica”. Tal atividade foi planejada e aplicada pelos discentes do Curso de Licenciatura em Química do Instituto Federal da Paraíba - IFPB - Campus João Pessoa, integrantes do projeto de pesquisa, o qual originou o trabalho em tela.

\section{FUNDAMENTAÇÃO TEÓRICA}

\section{Educação Inclusiva}

Para que a educação seja efetivamente inclusiva, para um discente com SD, esta deve englobar diversos fatores, tanto os relacionados à estrutura escolar, quanto os concernentes à 
relação entre a escola e a família. Para entender como a escola regular está preparada, nos dias atuais, para receber o discente com Síndrome de Down em uma perspectiva de educação inclusiva, é fundamental descrevermos sobre a Lei Brasileira de Inclusão - LBI.

A LBI $n^{0} 13.146$ foi emitida em 06 de julho de 2015, sendo considerada um marco histórico na educação inclusiva. No entanto, outros documentos governamentais, como a Constituição de 1988 e a Lei de Diretrizes e Bases - LDB nº 9.394/1996, já discorriam sobre os direitos das pessoas com deficiência, porém, de forma mais geral. Na Lei Brasileira de Inclusão, os direitos das pessoas com deficiência estão assegurados em seu capítulo IV, artigo 27:

\begin{abstract}
A educação constitui direito da pessoa com deficiência, assegurados sistema educacional inclusivo em todos os níveis e aprendizado ao longo de toda a vida, de forma a alcançar o máximo desenvolvimento possível de seus talentos e habilidades físicas, sensoriais, intelectuais e sociais, segundo suas características, interesses e necessidades de aprendizagem (BRASIL, 2015).
\end{abstract}

No entanto, o que se observa na prática, vai na contramão do que está disponibilizado nos documentos oficiais, ou seja, não existe uma inclusão eficaz nas escolas brasileiras.

\title{
Processo de Aprendizagem
}

O processo de ensino e aprendizagem para pessoas com Síndrome de Down é diferente, pois o desenvolvimento cognitivo é lento, este se dá de acordo com os estímulos que o indivíduo recebe, podendo desenvolver habilidades e potencialidades mais fortes em uma pessoa do que na outra. Dentro desse contexto, essas pessoas apresentam algumas especificidades:

\footnotetext{
A presença do cromossomo 21 extra na constituição genética determina características físicas específicas e atraso no desenvolvimento. Sabe-se que as pessoas com SD quando atendidas e estimuladas adequadamente, têm potencial para uma vida saudável e plena inclusão social. No Brasil nasce uma criança com SD a cada 600 e 800 nascimentos, independente de etnia, gênero ou classe social (BRASIL, 2012, p. $9)$.
}

Segundo Milani (2005, p. 50), “as conexões cerebrais das crianças portadoras da Síndrome de Down são mais lentas e fracas e por isso requerem mais repetições. [...]”. É de fundamental importância estimular corretamente as pessoas com SD, adotando a utilização de atividades que exijam mais da memória visual, da vivência, possuindo metodologia repetitiva, curta e objetiva e de materiais concretos/físicos, pois tais ações reafirmam a absorção do conteúdo, validando o processo de aprendizagem.

Um fator que auxilia o processo de detenção do saber é a utilização de recursos lúdicos/práticos, que reafirma o pressuposto do concreto, juntamente com a execução da ação pelo próprio discente Down, colocando-o como protagonista da ação, aflorando no mesmo o desejo pela obtenção da construção do conhecimento (CAVALCANTI, 2005). Nesse sentido, 
ao despertar a curiosidade aumenta-se o engajamento, a motivação intrínseca e a retenção do conteúdo pelo discente, ou seja, sua aprendizagem. Assim, a motivação seja ela extrínseca e intrínseca, tem papel fundamental e facilitador na aquisição de conceitos.

\section{METODOLOGIA}

O trabalho baseou-se na pesquisa qualitativa, com cunho participante. Segundo Marconi e Lakatos (2011, p. 191), a pesquisa participante "ajuda o pesquisador na identificação e obtenção de provas a respeito de objetivos sobre os quais os indivíduos não têm consciência, mas que orientam seu comportamento".

Enquanto que, "a pesquisa qualitativa preocupa-se em analisar e interpretar aspectos mais profundos, descrevendo a complexidade do comportamento humano. Fornece análise mais detalhada sobre as investigações, hábitos, atitudes, tendências de comportamento etc.” [...] (MARCONI e LAKATOS, 2011, p. 269).

A atividade foi desenvolvida e aplicada no Instituto Federal da Paraíba, Campus João Pessoa, e consistiu em um acompanhamento escolar, de uma discente que apresenta Síndrome Down, a qual possui 24 (vinte e quatro) anos, e está matriculada no $1^{\circ}$ ano do Curso Técnico Integrado ao Ensino Médio de Instrumento Musical. Tal acompanhamento discorreu numa aplicação do conteúdo de "Tabela Periódica", vislumbrando melhorar seu desempenho neste assunto alusivo à disciplina Química. Para isso, foi utilizada uma Tabela Periódica adaptada, construída com materiais alternativos e de baixo custo.

O acompanhamento foi realizado em horário oposto ao das aulas da discente e com a disponibilidade da mesma, para não afetar seu desempenho nas outras áreas. A aplicação foi feita em uma tarde, durante 2 horas, pelos integrantes da equipe de pesquisa, na presença dos pais da estudante Down.

\section{RESULTADOS E DISCUSSÃO}

Para a realização da atividade, foi utilizada uma Tabela Periódica adaptada (Figura 1), com o intuito de facilitar a leitura e a compreensão da discente com Síndrome de Down. Uma vez que, tal recurso lúdico trabalha com o concreto, tão eficaz no processo de aprendizagem, sendo um grande auxiliador e um instrumento imprescindível no acompanhamento do conteúdo supramencionado. 
Figura 1: Tabela Periódica adaptada.

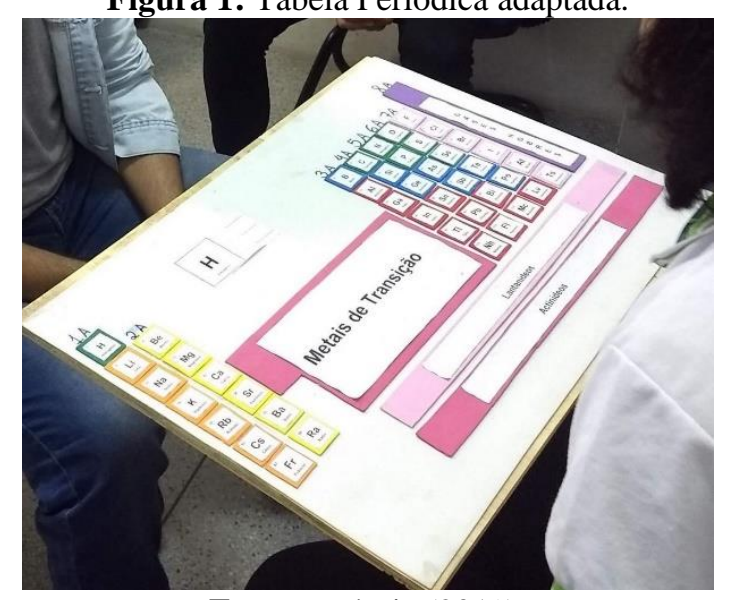

Fonte: Própria (2019).

Durante a atividade (Figura 2), notou-se a facilidade com que a estudante relacionava os nomes dos elementos químicos com os seus respectivos símbolos presentes na tabela. Nesse caso, evidencia-se que o uso de materiais adaptados pode contribuir de forma significativa ao ensino de Química para discentes com Down, facilitando ainda mais a inclusão no processo de aprendizagem (OLIVEIRA et al, 2013).

Figura 2: Apresentação da Tabela Periódica adaptada.

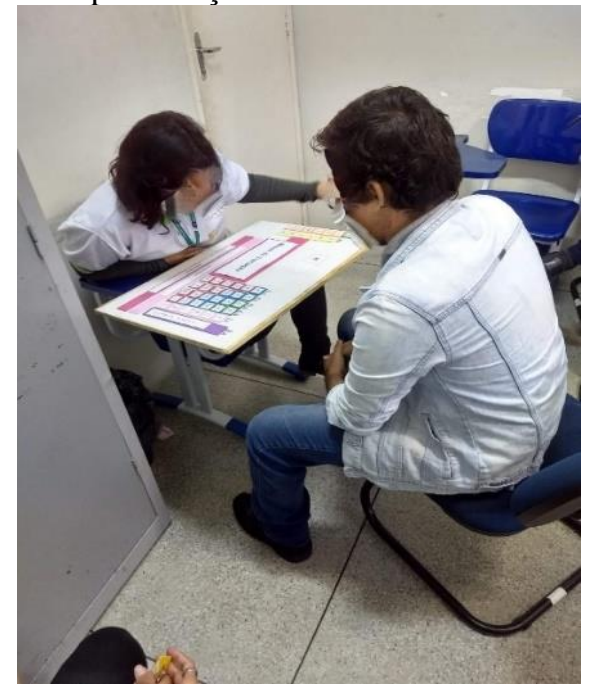

Fonte: Própria (2019).

No decorrer da explanação, foram realizadas perguntas relacionadas ao conteúdo periódico, realizadas de forma verbal com a discente, objetivando avaliar seu nível de aprendizagem. Desta forma, foi possível destacar pontos positivos, pois a discente mostrou entusiasmo para com o material que era de fácil visualização e entendimento.

Tal fato corrobora com Silva (2015), que afirma que a utilização de metodologias 
diferenciadas que estimulem a imaginação e a percepção visual depende da integração neurológica, o que consequentemente, promove a prontidão para o desenvolvimento cognitivo. Desse modo, foi notório que esse método foi capaz de engajar a discente com Síndrome de Down de maneira assertiva e desenvolver ainda mais seus conhecimentos na disciplina Química.

Assim, a discente Down conseguiu responder à todas as questões propostas e manteve 90\% de acertos, realizando a atividade, em todo momento, de forma descontraída e motivada. Vale lembrar que, em toda a execução da proposta, a discente foi devidamente acompanhada pelos pais, que concomitantemente com a equipe de pesquisa, auxiliou-a lendo o assunto, explicando e fazendo repetições para a técnica ser concluída com sucesso.

Fica elucidado, sobretudo, que a utilização de meios pedagógicos como o uso de recursos adaptados no ensino de Química para discentes com Down, pode garantir novas experiências e ajudá-los a desenvolver habilidades nunca antes adquiridas. Por conseguinte, é possível proporcionar a inclusão e colaborar devidamente com as práticas de ensino, garantindo uma melhor compreensão de disciplinas mais complexas e estimulando gradativamente a percepção desses discentes.

\section{CONCLUSÕES}

Durante a atividade, ficou elucidado o quão se faz necessário o uso de metodologias e recursos adaptados, utilizando o concreto, o lúdico, as cores, para uma melhor aprendizagem do educando com SD, pois tais recursos são fundamentais para um efetivo ensino inclusivo. Porém, a escola ainda carece de materiais didáticos inclusivos, esta observação é pertinente, pois é uma realidade enfrentada pela maioria delas, que não dispõem de materiais dessa natureza, nem de investimentos para suprir esse tipo de necessidade e tornar o ensino igualitário para todos.

Portanto, é importante pensar na escola para todos, garantindo a equidade do ensino, respeitando a diversidade e limitações das pessoas com deficiência. Só assim, a inclusão deixará de ser utópica e passará a ser realidade. Uma escola inclusiva aberta à riqueza da diversidade e consciente de suas funções sociais e políticas, se torna um espaço plural, capaz de promover profundas e intensas mudanças sociais.

\section{REFERÊNCIAS}

BRASIL. Diretrizes de atenção à pessoa com Síndrome de Down / Ministério da Saúde, Secretaria de Atenção à Saúde, Departamento de Ações Programáticas Estratégicas. - 
Brasília: Ministério da Saúde, 2012.

BRASIL. Lei Brasileira de Inclusão-LBI n 13.146/15: Estatuto da Pessoa com Deficiência. Brasília, 06 jul. 2015.

CAVALCANTI, L. S. Geografia e práticas de ensino. Goiânia: Alternativa, 2005. 127p.

MARCONI, M. A.; LAKATOS, E. M. Metodologia científica. $6^{\text {a }}$ ed. - São Paulo: Atlas, 2011.

MILANI, D. Down, Síndrome de: como - onde - quando - porquê. São Paulo: Livro Pronto: 2005.

OLIVEIRA, J. S. et al. Ensino de química inclusivo: Tabela periódica adaptada a deficientes visuais. 2013.

OLIVEIRA, C. Dia da Síndrome de Down revela evolução da inclusão no Brasil. 2015. Disponível em: http://portal.mec.gov.br/ultimas-noticias/202-264937351/21167-dia-dasindrome-de-down-revela-evolucao-da-inclusao-no-brasil. Acesso em 18 de outubro de 2019.

SILVA, A. M. E. C. et al. Um olhar sobre o processo de ensino e aprendizagem de crianças com síndrome de Down. Revista Includere, v. 1, n. 1, 2015. 


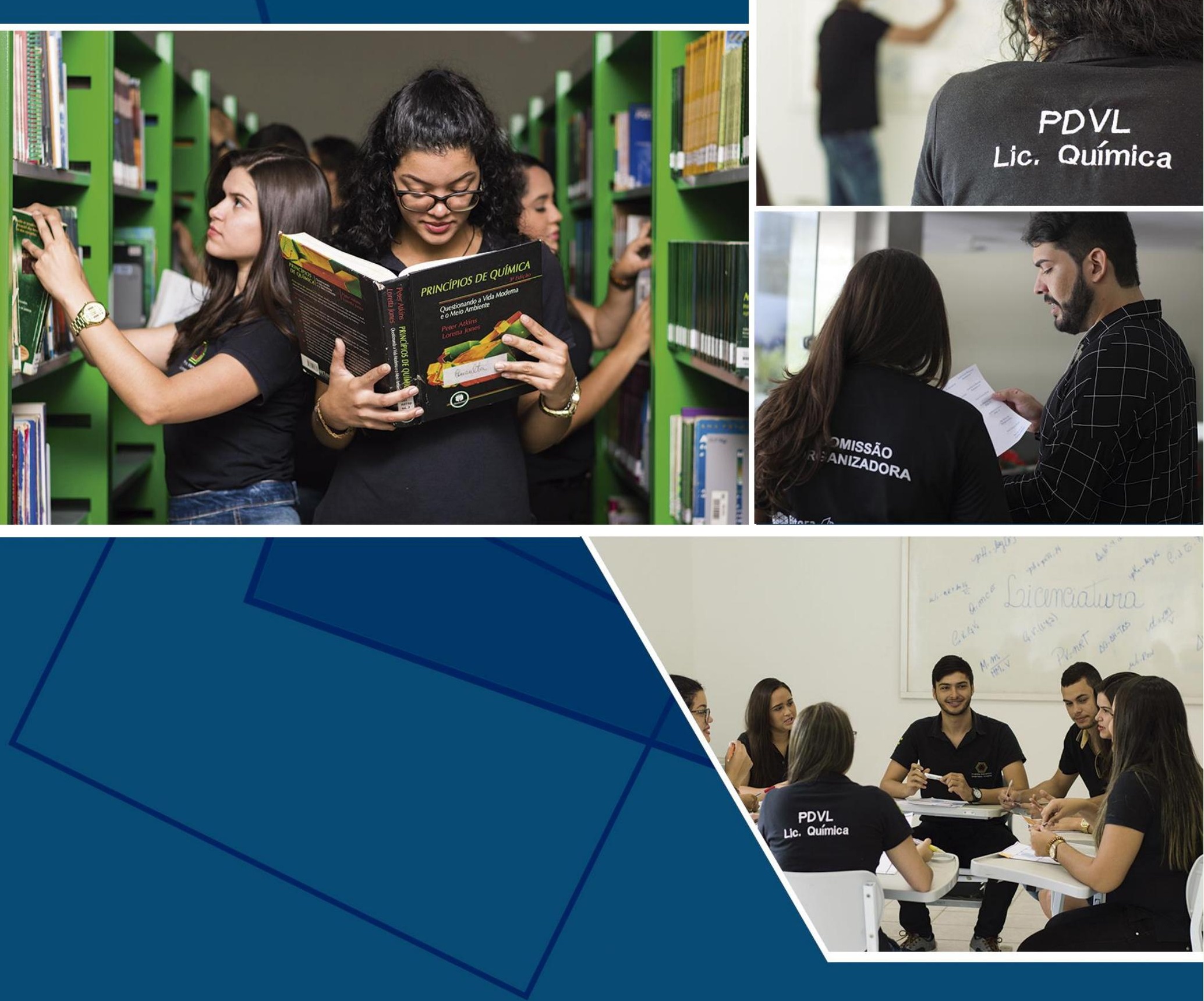

